\title{
Role of a Multichannel Electrotactile Speech Processor in a Cochlear Implant Program for Profoundly Hearing-impaired Adults*
}

\section{Q( $(11$}

Robert S. C. Cowan, MSc, DipAud; Peter J. Blamey, PhD; Julia Z. Sarant, BSc, DipAud; Karyn L. Galvin, BSc, DipAud; Joseph I. Alcantara, BSc, DipAud; Lesley A. Whitford, BSc, DipAud; Graeme M. Clark, PhD, FRACS

From the Department of Otolaryngology, University of Melbourne, Parkville, Victoria, Australia (R. S. C. C., P. J. B., J. Z. S., K. L. G., J. I. A., G. M. C.); and Cochlear Pty. Ltd., Lane Cove, NSW, Australia (L. A. W.)

\section{ABSTRACT}

Four profoundly hearing-impaired adults who did not meet current selection criteria for implantation at the University of Melbourne were each fitted with a wearable multichannel electrotactile speech processor (Tickle Talker). The subjects were evaluated with a test battery of speech discrimination tests subsequent to training in use of the device. Thresholds for detection of pure tones were lower for the Tickle Talker than for hearing aids across the frequency range 250 to $4000 \mathrm{~Hz}$. Mean speech detection thresholds for the Ling 5-sound test showed that all sounds were detected by users of the electrotactile device at normal conversational speech intensity levels. Mean speech discrimination scores were significantly higher $(p<0.05)$ in the tactually aided condition as compared with the tactually unaided for identification of vowels and consonants, on open-set words, open-set sentences, and on connected discourse tracking. Mean scores increased by $20 \%$ for vowels, $19 \%$ for consonants, $30 \%$ for openset words, and $25 \%$ for open-set sentences when the Tickle Talker was used in a multimodal combination with lipreading or lipreading and hearing aids. Speechtracking rates for three subjects showed increases of from 18 to $28 \mathrm{wpm}$ when the tactile device was used. Comparison of tactually aided versus unaided tracking rates for two subjects with long-term experience shows continuing improvement with additional experience with the device. These results demonstrate that hearing-impaired adults not meeting selection criteria for cochlear implantation may benefit from use of an electrotactile speech proces- sor, and highlight the potential benefits from integration of such devices into cochlear implant programs for profoundly hearing-impaired patients. (Ear Hear 12 1:39-46)

SEVERAL CLINICAL STUDIES have demonstrated improved speech discrimination for profoundly hearing-impaired adults using the University of Melbourne multichannel cochlear implant in combination with lipreading (Dowell, Mecklenburg, \& Clark, 1986; Dowell, Martin, Clark, \& Brown, 1985; Dowell, Seligman, Blamey, \& Clark, 1987). Further, some adults are able to perceive connected speech without lipreading using only a multichannel hearing prosthesis (Dowell, Clark, Seligman, \& Brown, 1986). Based on experimental results and clinical experience with adults currently using the 22-channel cochlear implant, initial implant patient selection criteria (Clark et al, 1988) have been reviewed, and implantation has been extended to include some prelingually hearing-impaired patients and patients receiving up to $20 \%$ on open-set sentence tests (word score) with hearing alone (Pyman, Brown, Dowell, \& Clark, 1990). However, some patients may still not meet selection criteria due to radiological contraindications to surgery, negative results for electrical stimulation of the promontory or sociological contraindications. In addition, medical complications during or subsequent to implantation may necessitate removal of the device. Further, although patients scoring better than $20 \%$ on open-set word tests with hearing alone are not considered for implantation, they may still require additional assistance to that provided by conventional hearing aids. This is due to the tendency for sensorineural losses to show greater impairment for the higher frequency, lower acoustic energy consonant sounds, which are especially important for speech discrimination, and the limitations of current amplification systems in providing this information within the tolerance limits of the patient.

\footnotetext{
" Financial support for this research was from Cochlear Pty. Ltd., the Department of Industry, Technology and Commerce, and Department of Employment, Education and Training of the Australian Government, the National Health \& Medical Research Council, the Deafness Foundation (Victoria), the George Hicks Foundation, and the lan Potter Foundation.
}

0196/0202/91/1201-0039\$03.00/0 • EAR AND HEaring Copyright $(1991$ by The Williams \& Wilkins Co. - Printed in U.S.A. 
In order to provide assistance to this group of "nonimplantable" hearing-impaired adults, a wearable electrotactile speech processor has been developed in Australia by the University of Melbourne (Blamey \& Clark, 1985). The battery powered device presents speech information through the tactual modality as a pattern of biphasic constant current $(1.5 \mathrm{~mA})$ electrical pulses. Stimuli are presented through eight stainless steel electrodes positioned in rings on the skin surface over the digital nerve bundles on the two sides of the four fingers of the nondominant hand (a common ground electrode is located at the wrist). The speech processor/stimulator was modeled on the University of Melbourne multichannel cochlear implant, and uses similar hardware. Psychophysical tests have indicated that the device could encode similar speech features to those used successfully by implant patients (Blamey \& Clark, 1987). Second format frequency is encoded as electrode position, speech waveform amplitude as electrical pulse duration and fundamental frequency as pulse rate. Initial evaluations have shown improved speech discrimination scores for trained users on both closed-set speech feature tests and open-set words, sentences and connected speech, when the device is used in combination with lipreading (Cowan, Alcantara, Blamey, \& Clark, 1988), or lipreading and aided residual hearing (Cowan et al, 1989). These results were found for both artificially deafened normally hearing subjects and a small group of profoundly hearing-impaired adults.

The present study was undertaken to establish whether hearing-impaired adults who do not meet selection criteria for cochlear implantation might benefit from fitting of the multichannel electrotactile speech processor as an alternative.

\section{METHOD}

\section{Subjects}

A brief profile of the four hearing-impaired subjects is given below and in Table 1. Each subject was referred from the cochlear implant clinic at the University of Melbourne.

Subject 1 was an 81 year old male, totally deaf for 15 years from a step-wise progressive loss due to possible otosclerosis. He had been implanted with a Nucleus multichannel cochlear implant in 1982, but a full set of electrodes could not be used due to degeneration of the bony structure of the cochlea. Symptoms of facial paralysis developed in early 1986, and a CATscan detected the presence of an acoustic neuroma on the implanted right side. The neuroma was surgically removed and the implant was removed in May 1986. Involvement of the facial nerve resulted in some residual visual problems. The subject's left ear was deemed unsuitable for cochlear implantation due to ossification of the cochlea and the patient's general health.

Subject 2 was a 31 year old male, totally deaf since age 4 due to meningitis. Although meeting medical/audiological criteria for implantation, he elected not to proceed with surgery.

Subject 3 was a 27 year old male, profoundly hearingimpaired since birth. He wore a single postauricular hearing aid on the left ear. Although a right ear fitting was assessed, tolerance problems were encountered. Assessment showed hearing-alone, open-set word scores of $30 \%$, which did not meet selection criteria regarding usable residual hearing.

Subject 4 was a 53 year old female. profoundly hearingimpaired for 3 years as a result of head injuries. She wore a single postauricular hearing aid on the right ear. Aided thresholds for the right ear were within the speech range from 250 to $4000 \mathrm{~Hz}$. No auditory response was measured on the left ear at audiometer output limits. However, subject 4 scored $0 \%$ on open-set words for hearing alone, and showed no improvement when hearing was combined with lipreading. ABR testing suggested brain stem level dysfunction; however, results of CAT scans were negative for acoustic neuroma. However, the right ear was deemed unsuitable for implantation due to the level of aided thresholds obtained, and the possibility of higher order neural dysfunction. Promontory stimulation results for the left ear were poor, contraindicating implantation of the left ear.

\section{Procedure}

Following several initial sessions to establish consistent thresholds and dynamic ranges for electrotactile stimulation, each of the four subjects was fitted with a wearable electrotactile device, and commenced the clinical training program. This program includes an ordered set of speech feature recognition exercises and conversational-type training. Subjects 1,2 , and 3 had completed the formal training program (45 hr approximately), whereas subject 4 had been fitted more recently, and had received approximately $25 \mathrm{hr}$ training prior to the evaluations reported here.

The evaluation included a range of tests designed to assess the overall contribution of the tactual information to speech discrimination. Sound awareness thresholds with the Tickle Talker were measured for short duration $(1 \mathrm{sec})$ pure tones presented free-field using a hand-held pure-tone generator. In addition, speech detection thresholds for the Ling 5-sound test (Ling \& Ling, 1978) were measured for live-voice presentations by a speaker familiar to the subjects. Threshold levels were measured in $\mathrm{dB} A$-weighted sound pressure level by a Quest Electronics sound-level meter and were then converted to dB SPL for comparison with aided thresholds for hearing aids. Speech discrimination tests included both closed- and open-set speech materials, prerecorded on videocassette. In addition, measures of live-voice connected speech tracking (CDT) (DeFilippo \& Scott, 1978) were used as part of the training program and for monitoring communication benefit when the device was combined with lipreading or lipreading plus aided residual hearing. Closed-set materials included discrimination of 11 vowels in $/ \mathrm{hVd} /$ format and 12 consonants in $/ \mathrm{aCa}$ / format. Open-set materials included $\mathrm{AB}$ words (Boothroyd, 1968), scored both phonemically and by whole words, and BKB sentences (Bench \& Bamford, 1979), scored both by key words and by whole sentences. In addition, subject 3 was tested with Harvey-Gardner high-frequency word lists (Gardner, 1971) to assess the contribution of the tactile device on a test requiring accurate discrimination of high frequency consonant information. These word lists, originally developed to assess efficiency of high-frequency emphasis hearing aids, have been shown to be sensitive to highfrequency hearing losses (Mecklenburg, 1979). Speechtracking rates in words per minute were averaged over the last five sessions for both the tactually aided and tactually unaided conditions. Tracking rates were measured over 5 minute sessions in both conditions. Patient 1 was not assessed with 
speechtracking as his visual problems resulting from surgery made this task too difficult.

Each test was performed in the tactually aided and tactually unaided conditions. For subjects 1 and 2, the tactually unaided condition consisted of lipreading only (L). since neither subject wore hearing aids and so received no auditory information. The tactually aided condition for subjects 1 and 2 consisted of combined input from lipreading and the Tickle Talker (TL). Subjects 3 and 4 used the combination of lipreading and aided residual hearing (LA) in the tactually unaided condition, whereas the tactually aided condition consisted of multimodal input from Tickle Talker, lipreading and hearing aids (TLA)

In addition, a tracking rate difference score between tactually-aided and unaided speechtracking rates was calculated for weekly training sessions over a period of 28 weeks for subject 2 and 43 weeks for subject 3 , both of whom had received long-term training and home-usage of the device. In each of these sessions, speechtracking rates were measured for 5 minute segments in both conditions, and the difference between tracking rates was plotted over time.

During testing, the subject sat in a sound-chamber, approximately $1 \mathrm{~m}$ from the television monitor (recorded tests) or audiologist (speechtracking). Input to the speech processor was through the subject's lapel microphone, and the subjects were instructed to adjust the speech processor sensitivity control to their preferred setting. Input level was measured with a sound-level meter and was maintained at $65 \mathrm{dBA}$. Test items were not repeated, and no feedback on performance was provided throughout the evaluation. Use of test lists and order of presentation of conditions were balanced across the four subjects.

\section{RESULTS}

Individual aided thresholds for hearing aids and sound-field detection levels with the Tickle Talker are shown in Table 1. As shown, while results varied with the particular subject, thresholds overall were at lower levels for the Tickle Talker than for hearing aids across the frequency range from 250 to $4000 \mathrm{~Hz}$. Subjects 1 and 2 , who receive no auditory information, were able to detect sounds through the tactual display across the frequency range. Subjects 3 and 4 responded at lower levels for the tactile input as compared with hearing aids alone. This was especially evident in the case of subject 3 for stimuli above $2000 \mathrm{~Hz}$, where hearing aid responses were at much higher levels. Table 2 shows mean tactile speech detection thresholds for the Ling 5-sound test. As shown, speech detection thresholds were within the normal speech intensity range for all five sounds, indicating that the users would be detecting these sounds in normal conversational speech through the Tickle Talker set at everyday usage sensitivity levels.

Mean test battery results for the four subjects are shown in Table 3. Results of paired $t$-tests show a significant difference $(p<0.05)$ between tactually aided and unaided conditions for all tests. Group means improved by $20 \%$ for vowels and consonants, $30 \%$ for $\mathrm{AB}$ words (whole words), and $23 \%$ for $\mathrm{BKB}$ sentences (whole sentence). In addition, mean speechtracking rates increased by $18 \mathrm{wpm}$ for three subjects.
Table 1. Audiological data for four profoundly hearing-impaired subjects (unaided thresholds in AB HL re: ANSI-1969; aided thresholds free-field in $\mathrm{dB} S \mathrm{SPL}$, binaurally for subjects 1 and 2 and aided ear only for subjects 3 and 4 ; tactile thresholds free-field in dB SPL). NR: no response at $110 \mathrm{~dB}$ HL re: ANSI-1969.

\begin{tabular}{|c|c|c|c|c|c|c|}
\hline \multirow{2}{*}{ Subject } & \multirow{2}{*}{ Test } & \multicolumn{5}{|c|}{ Frequency $(\mathrm{Hz})$} \\
\hline & & 250 & 500 & 1000 & 2000 & 4000 \\
\hline \multirow[t]{3}{*}{1} & Unaided (better ear) & NR & NR & NR & NR & NR \\
\hline & Aided (binaural) & $110^{v}$ & NR & NR & NR & NR \\
\hline & Tactile threshold & 40 & 41 & 43 & 39 & 34 \\
\hline \multirow[t]{3}{*}{2} & Unaided (better ear) & $95^{\vee}$ & NR & NR & NR & NR \\
\hline & Aided (binaural) & NR & NR & NR & NR & NR \\
\hline & Tactile threshold & 38 & 38 & 40 & 37 & 33 \\
\hline \multirow[t]{4}{*}{3} & Unaided (right ear) & 70 & 85 & 100 & 110 & NR \\
\hline & Unaided (left ear) & 50 & 75 & 100 & 105 & NR \\
\hline & Aided (left ear) ${ }^{a}$ & 43 & 53 & 51 & 84 & NR \\
\hline & Tactile threshold & 53 & 43 & 35 & 39 & 34 \\
\hline \multirow[t]{4}{*}{4} & Unaided (right ear) & 90 & 90 & 85 & 85 & 75 \\
\hline & Unaided (left ear) & NR & NR & NR & NR & NR \\
\hline & Aided (right ear) & 82 & 67 & 50 & 50 & 43 \\
\hline & Tactile threshold & 62 & 48 & 44 & 43 & 52 \\
\hline
\end{tabular}

a Subject 3 did not use a hearing aid on the right ear due to tolerance problems.

${ }^{v}$ Denotes vibrotactile sensation.

Table 2. Mean speech detection thresholds for the Ling 5-sound test for four profoundly hearing-impaired subjects using a multichannel electrotactile speech processor, measured free-field in dB SPL.

\begin{tabular}{cccccc}
\hline & $/ \mathrm{u} /$ & $\mid \mathrm{a} /$ & $\mid \mathrm{i} /$ & $\mid \mathrm{f} /$ & $/ \mathrm{s} /$ \\
\hline Mean threshold & 39 & 37 & 37 & 37 & 41 \\
\hline
\end{tabular}

Individual test battery scores are shown for the four subjects as Figures 1 to 4 . Results are in percent, with the exception of speechtracking, which is measured in words per minute using the same scale as for percentage scores. Results for subjects 1 and 2 show substantial improvement on each test when the tactile device is combined with lipreading (TL) as compared with lipreading alone $(\mathrm{L})$. As mentioned previously, patient 1 had visual problems resulting from facial nerve involvement in an acoustic neuroma, and this may be partly responsible for the lower lipreading scores on all tests. Subjects 3 and 4 also show improvement on all tests for the combination of the tactile device with lipreading and aided residual hearing (TLA) as compared with the tactually unaided condition (LA), except in the case of subject 3 , whose tactually unaided vowel discrimination score reached $100 \%$. It is of note that subject 3 scored $100 \%$ in the tactually aided condition for vowels, consonants, open-set words, and sentences. Subject 3 also showed higher scores on the Harvey Gardner highfrequency word test in the tactually aided condition. Subject 4 shows improvements in the tactually aided condition for vowels, consonants, open-set words and sentences, and for speechtracking. Improvements were somewhat smaller than for the other subjects, especially 
Table 3. Mean scores on closed- and open-set speech tests for four profoundly hearing-impaired subjects using a multichannel electrotactile speech processor (tactually aided: TLA or TL; tactually unaided: $L A$ or $L$ ).

\begin{tabular}{|c|c|c|c|c|}
\hline Test & $n$ & $\begin{array}{c}\text { Tactually } \\
\text { Aided }\end{array}$ & $\begin{array}{l}\text { Tactually } \\
\text { Unaided }\end{array}$ & Significant Difference \\
\hline Vowels & 4 & $89 \%$ & $69 \%$ & $p<0.05, t=2.41, \mathrm{df}=3$ \\
\hline Consonants & 4 & $70 \%$ & $51 \%$ & $p<0.05, t=2.42, \mathrm{df}=3$ \\
\hline \multicolumn{5}{|l|}{ AB words } \\
\hline (phoneme) & 4 & $84 \%$ & $57 \%$ & $p<0.05, t=3.15, \mathrm{df}=3$ \\
\hline (word) & 4 & $65 \%$ & $35 \%$ & $p<0.005, t=7.35, \mathrm{df}=3$ \\
\hline \multicolumn{5}{|l|}{ BKB sentence } \\
\hline (key word) & 4 & $77 \%$ & $62 \%$ & $p<0.05, t=3.15, \mathrm{df}=3$ \\
\hline (sentence) & 4 & $66 \%$ & $41 \%$ & $p<0.001, t=10.23, \mathrm{df}=3$ \\
\hline Speechtracking & 3 & $60 \mathrm{wpm}$ & 42 wpm & $p<0.005, t=3.58, \mathrm{df}=2$ \\
\hline HG words & 1 & $75 \%$ & $54 \%$ & \\
\hline
\end{tabular}

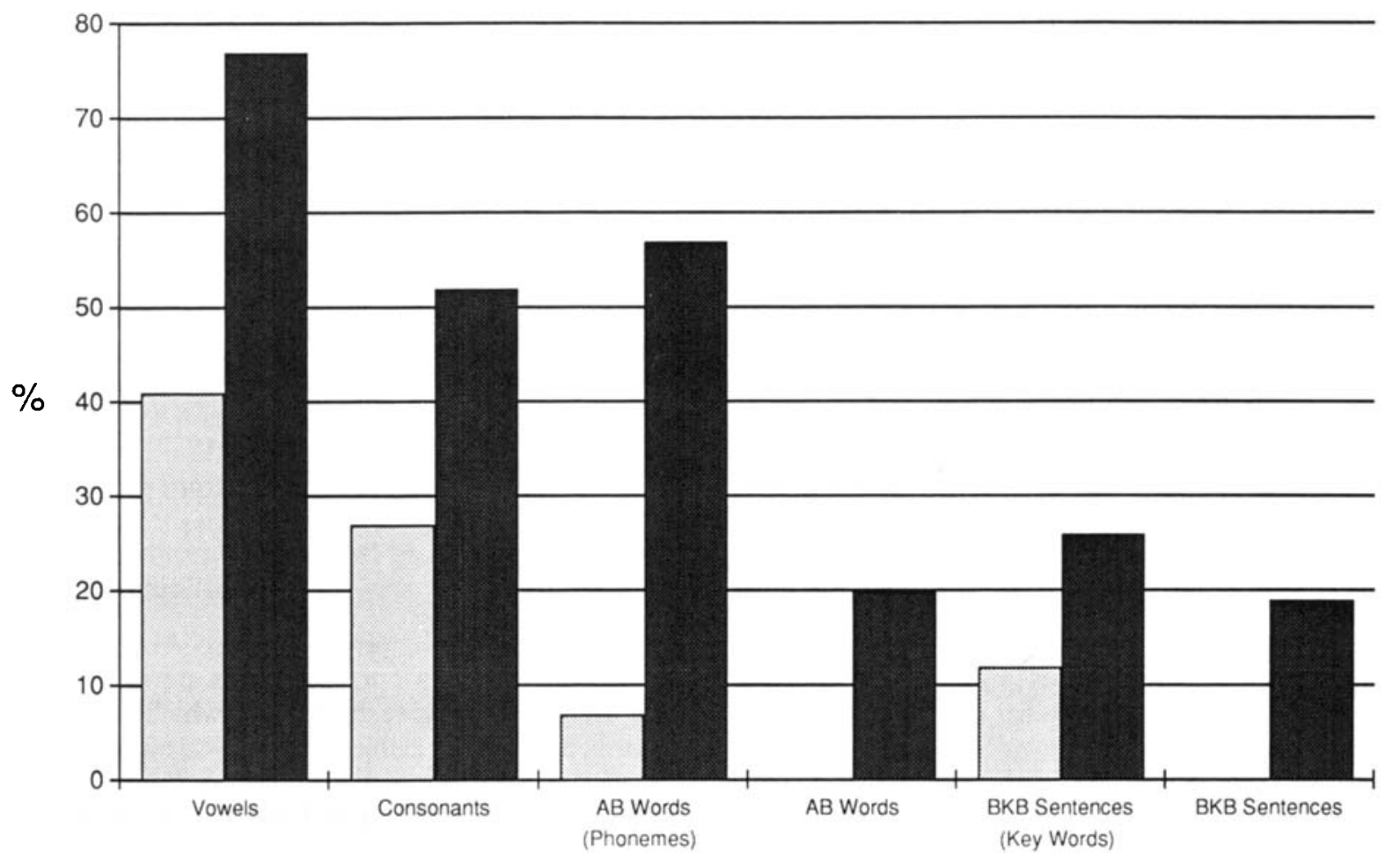

Figure 1. Individual speech discrimination scores for subject 1 using the multichannel electrotactile speech processor. ( $\square$ ), TL: tactually-aided; (畻), L, lipreading alone.

in the case of speechtracking. This may in part be due to fewer hours of training and experience for subject 4 .

Figures 5 and 6 show difference scores between tactually aided and unaided speechtracking rates measured over long-term training for subjects 2 and 3. As shown, tracking rates were variable between sessions, resulting in low correlation coefficients for the simple fit regression lines for both subject $2(r=0.543, b=0.5549)$ and subject $3(r=0.376, b=0.2367)$. However, statistical analysis of the regression equation shows a significant increase in tracking rate difference between the tactually aided versus unaided conditions with additional sessions (subject 2: $t=3.30, \mathrm{df}=26, p<0.005$; subject 3: $t=2.60, \mathrm{df}=40, p<0.01$ ).

\section{DISCUSSION}

The results of this study demonstrate that the four hearing-impaired adults, who did not meet selection criteria for cochlear implantation, did show substantial benefit from fitting with the multichannel electrotactile speech processor. Although individual results varied, benefits were obtained for sound and speech detection, speech feature recognition, and for discrimination of open-set words and sentences. In addition, two of the subjects, who had received substantial training with the device, showed significant improvements on a speechtracking test measured over time. While individual rates varied between sessions, reflecting differences in partic- 


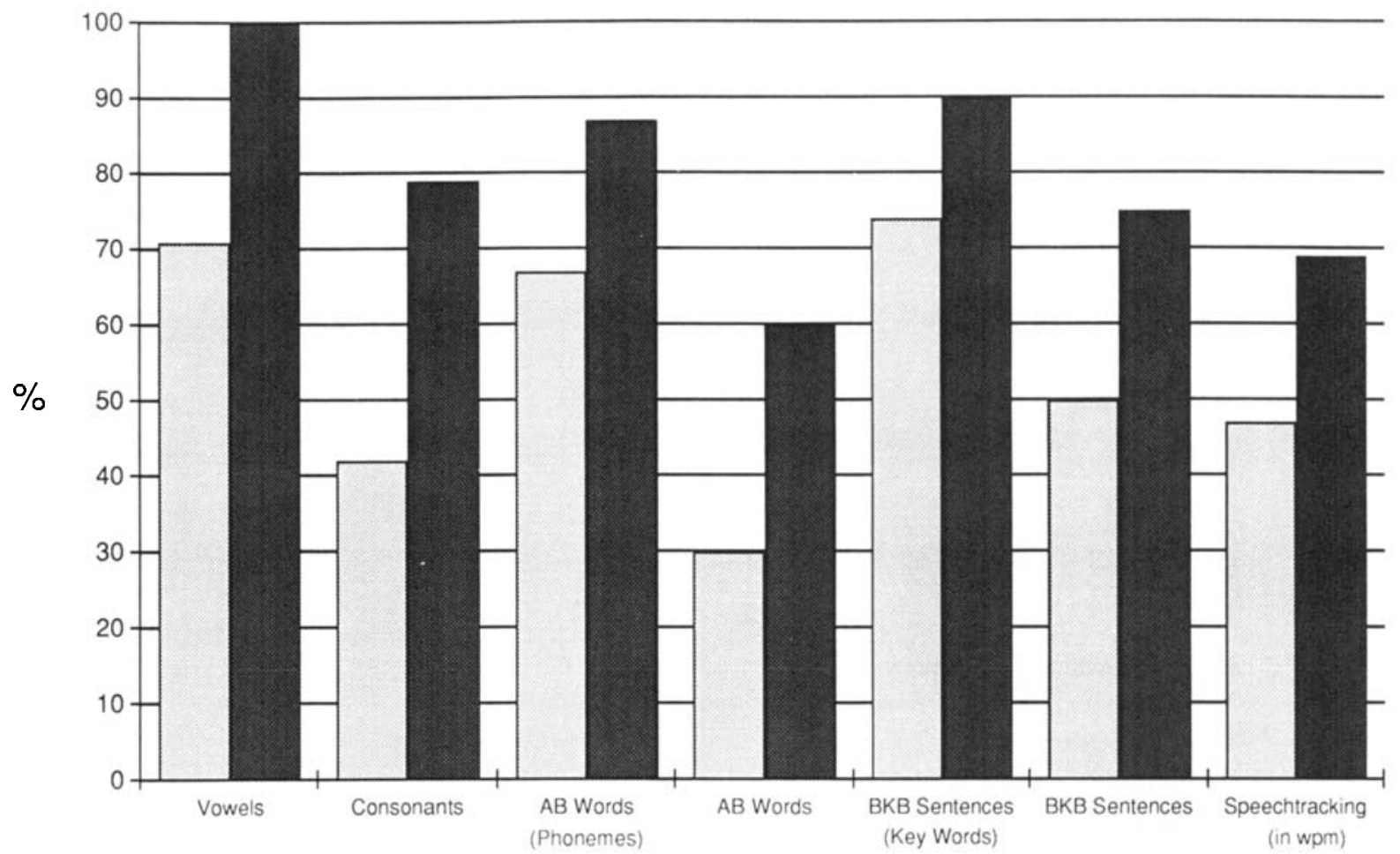

Figure 2. Individual speech discrimination scores for subject 2 using the multichannel electrotactile speech processor. ( $\square$ ), TL: tactually-aided; (椟), L: lipreading alone.

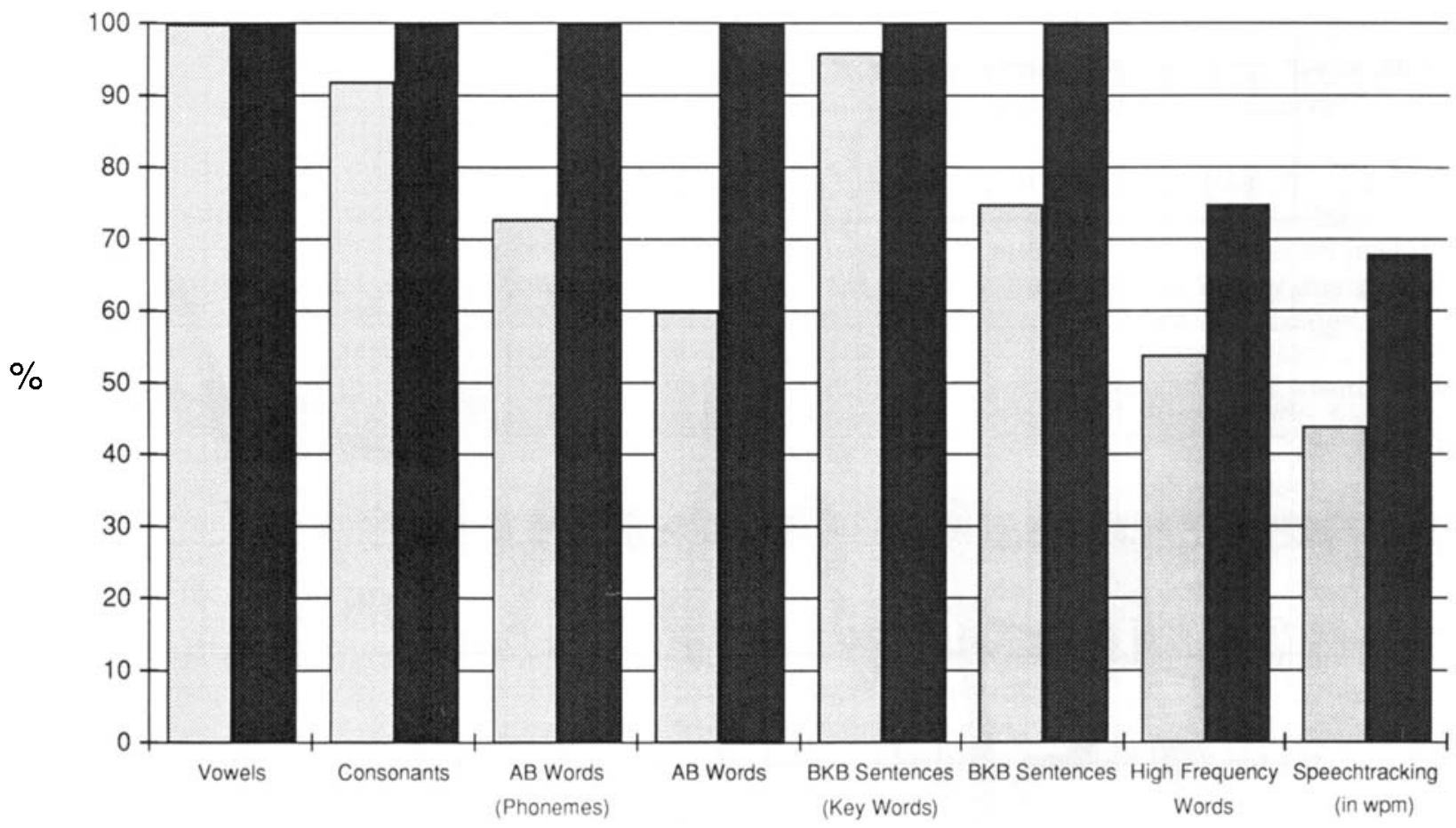

Figure 3. Individual speech discrimination scores for subject 3 using the multichannel electrotactile speech processor. ( $\square$ ), TLA: tactually-aided; (圈), LA: lipreading plus hearing aid.

ular text complexity, differences in speechtracking rates demonstrate progressive increases in the amount of benefit provided by the tactile device with additional experience. A third subject has also begun to show consistent improvements in speechtracking rates following $25 \mathrm{hr}$ of training. These results are consistent with previous findings which indicated that substantial training was required with the tactile device before 


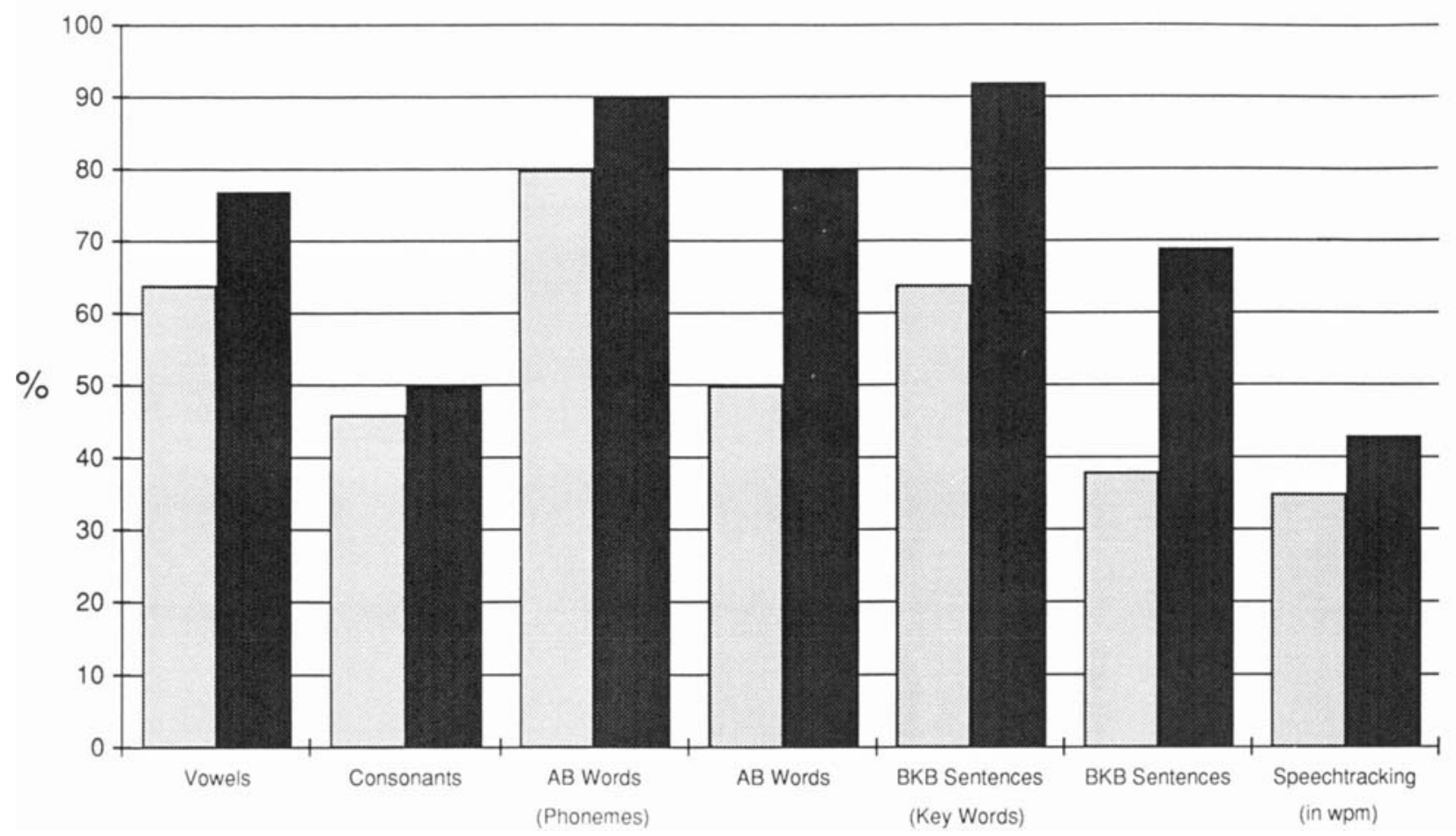

Figure 4. Individual speech discrimination scores for subject 4 using the multichannel electrotactile speech processor. ( $\square$ ), TLA: tactually-aided;

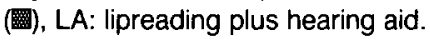

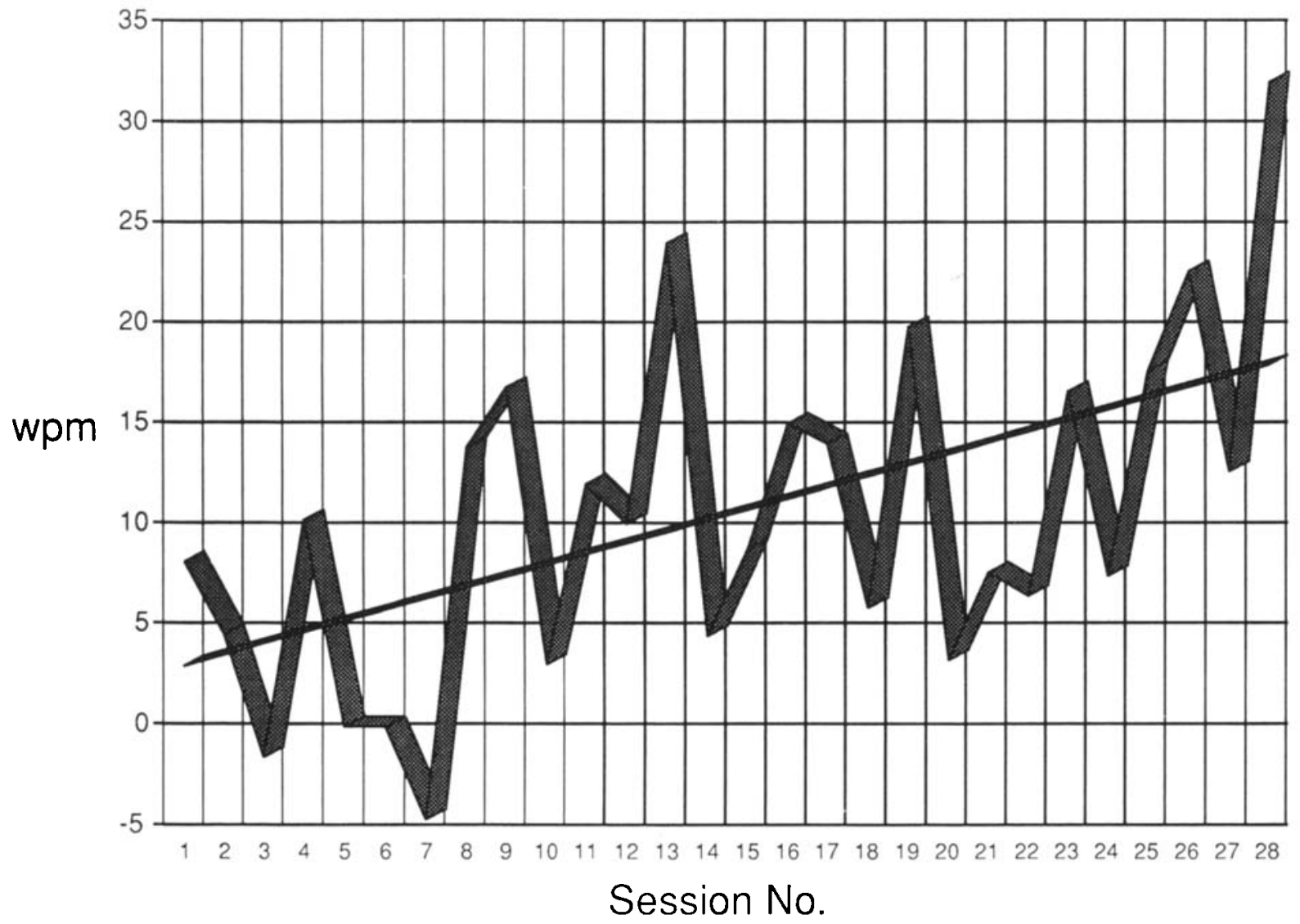

Figure 5. Difference scores in words per minute (wpm) between tactually aided $(T L)$ and unaided $(L)$ speechtracking rates for subject 2. Each point represents the difference in tracking rates between the two conditions for a 5 minute session. (圈), Subtraction TL/L; ( $)$ ), simple fit regression. 


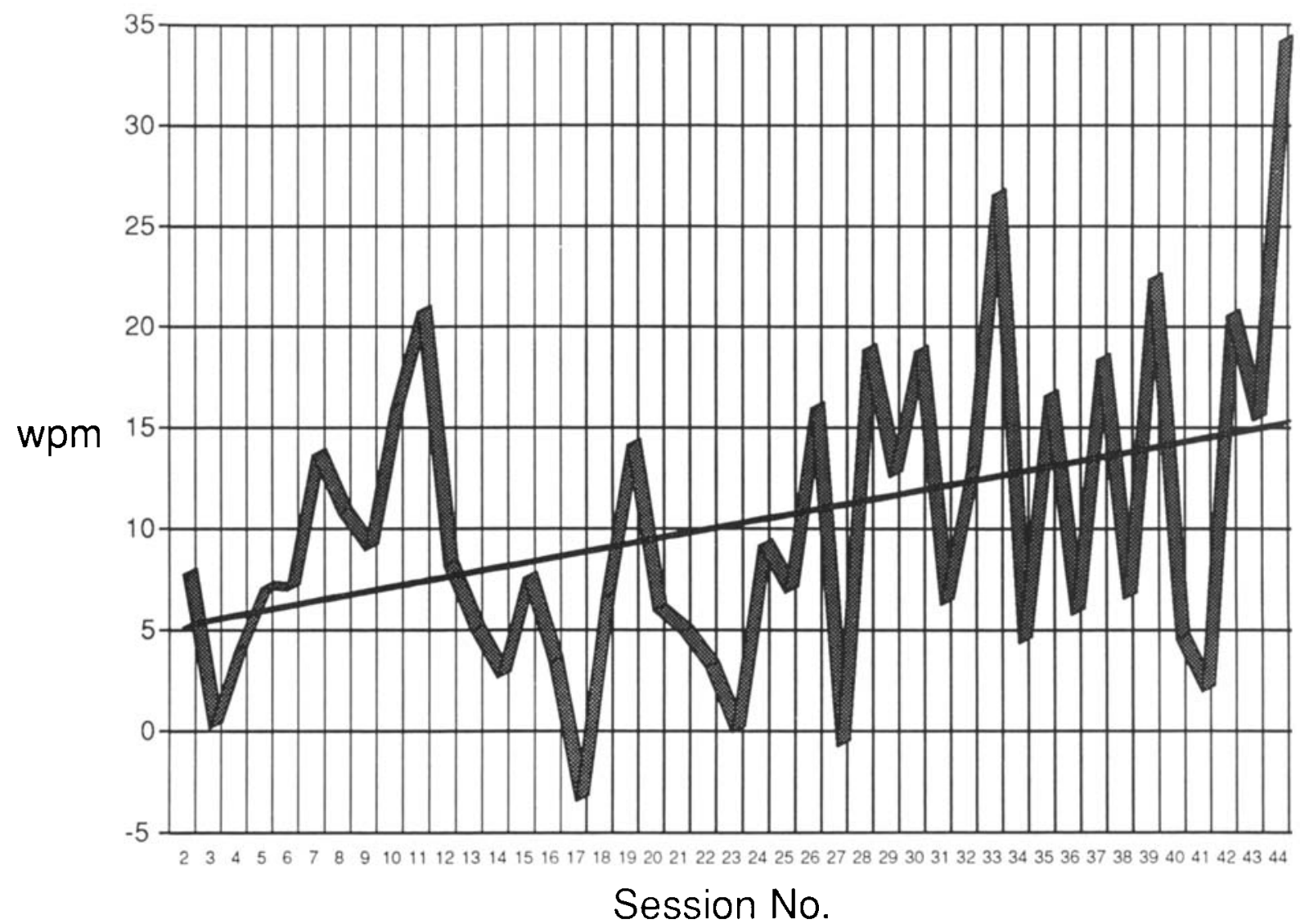

Figure 6. Difference scores in words per minute (wpm) between tactually aided (TLA) and unaided (LA) speechtracking rates for subject 3 . Each point represents the difference in tracking rates between the two conditions for a 5 minute session. (滆), Subtraction TLA/LA; ( $)$ ), simple fit regression.

open-set speech discrimination improvements could be expected (Blamey et al, 1989; Cowan et al, 1988, 1989). The results show that trained users can combine speech feature information presented through the tactual modality with information available from lipreading (subjects 1 and 2) or the combination of lipreading and aided residual hearing (subjects 3 and 4 ), and that this multimodal input combination can improve discrimination of words and sentences. Similar improvements in speech discrimination have been reported for a group of fifteen prelingually profoundly hearing-impaired children using the multichannel Tickle Talker (Cowan et al, 1990).

The results are also consistent with recent reviews of tactual aid development which clearly demonstrate that speech information can successfully be transmitted through the tactual modality (Hanin, Boothroyd, \& Hnath-Chisholm, 1988; Lynch, Oller, \& Eilers, 1989; Reed, Durlach, Delhorne, Rabinowitz, and Grant, 1989; Weisenberger, 1989). However, as pointed out in Levitt (1988), the history of tactual aid development has been marked by cyclical periods of interest and activity. Although researchers such as Pickett and Stark (1987) suggest that multichannel tactile devices be considered as prime alternatives to multichannel cochlear implants until the relative merits of different devices are more clearly established, there remains a concern that educators, audiologists and otologists may conceive of the cochlear implant as obviating any necessity for further development or usage of tactual devices.

The results of the present study clearly demonstrate that for hearing-impaired adults not meeting selection criteria for implantation, clear benefits for speech discrimination were obtained through use of the multichannel electrotactile speech processor as an alternative. This benefit was available to patients not meeting current audiological, medical, or sociological selection criteria. Severely to profoundly hearing-impaired adults, who may not receive all speech information through their hearing aids, would also not benefit from usage of single-channel tactual devices, since much of the time/intensity information presented would be redundant with information from hearing aids. This suggests a clear advantage for clinics involved in the rehabilitation of profoundly hearing-impaired adults to have access both to the multichannel cochlear prosthesis and multichannel electrotactile speech processor.

\section{REFERENCES}

ANSI. Specifications for audiometers. ANSI S3.6, American National Standards Institute, New York, 1969. 
Bench J and Bamford J. Speech-hearing Tests and the Spoken Language of Hearing-Impaired Children. London: Academic, 1979.

Blamey PJ and Clark GM. A wearable multiple-electrode electrotactile speech processor for the profoundly deaf. J Acoust Soc Am 1985;77:1619-1620.

Blamey PJ and Clark GM. Psychophysical studies relevant to the design of a digital electrotactile speech processor. J Acoust Soc Am 1987:82:116-125.

Blamey PJ, Cowan RSC, Alcantara JI, Whitford LA, and Clark GM. Speech perception using combinations of auditory, visual and tactual information. J Rehabil Res Dev 1989:26:15-24

Boothroyd A. Developments in speech audiometry. Sound (now $\mathrm{Br}$ J Audiol) 1968;2:3-10.

Clark GM, Blamey PJ, Brown AM, Busby PA. Dowell RC, Franz BK-H, Millar JB, Pyman BC, Shepherd RK, Tong YC, Webb RL, Brimacombe JA, Hirshorn MS, Kuzma J, Mecklenburg DJ. Money DK, Patrick JF, and Seligman PM. The University of Melbourne/ Nucleus cochlear prosthesis. Aust NZ J Surg 1988:58:89-102.

Cowan RSC, Alcantara JI. Blamey PJ, and Clark GM. Preliminary evaluation of a multichannel electrotactile speech processor. J Acoust Soc Am 1988;83:2328-2338.

Cowan RSC, Alcantara JI, Whitford LA, Blamey PJ, and Clark GM. Speech perception studies using a multichannel electrotactile speech processor, residual hearing and lipreading. J Acoust Soc Am 1989:85:2593-2607.

Cowan RSC, Blamey PJ, Galvin KL, Sarant JZ, Alcantara JI, and Clark GM. Perception of sentences, words and speech features by profoundly hearing-impaired children using a multichannel electrotactile speech processor. J Acoust Soc Am 1990;88:1374-1384.

DeFilippo CL and Scott BL. A method for training and evaluating the reception of ongoing speech. J Acoust Soc Am 1978;64:11861192.

Dowell RC, Martin LFA, Clark GM, and Brown AM. Results of a preliminary clinical trial on a multi-channel cochlear prosthesis. Ann Otol Rhinol Laryngol 1985;94:244-250.

Dowell RC, Mecklenburg DJ, and Clark GM. Speech recognition results for 40 multichannel cochlear implants in the U.S.A. and Australia. Arch Otolaryngol 1986;112:1054-1059.

Dowell RC, Clark GM, Seligman PM, and Brown AM. Perception of connected speech without lipreading, using a multichannel hear- ing prosthesis. Acta Otolaryngol (Stockh) 1986:102:7-11.

Dowell RC. Seligman PM. Blamey PJ, and Clark GM. Speech perception using a two-format 22-electrode cochlear prosthesis in quiet and in noise. Acta Otolaryngol (Stockh) 1987:104:439-446.

Gardner HJ. Application of a high-frequency consonant discrimination word list in hearing aid evaluation. J Speech Hear Disord 1971:8:92-93.

Hanin L, Boothroyd A, and Hnath-Chisholm T. Tactile presentation of voice fundamental frequency as an aid to speechreading of sentences. Ear Hear 1988:9:335-341.

Levitt $H$. Recurrent issues underlying the development of tactile sensory aids. Ear Hear 1988;9:301-305.

Ling D and Ling AH. Aural Habilitation. Washington, DC: AG Bell Association for the Deaf, 1978.

Lynch MP. Oller DK, and Eilers RE. Portable tactile aids for speech perception. Volta Rev Monograph 1989;91(5):113-126.

Mecklenburg DJ. Validity study on Harvey Gardner's high frequency consonant discrimination word lists. Aust J Human Comm Disord 1979;7:34-79.

Pickett JM and Stark RE. Cochlear implants and sensory aids for deaf children. Intl J Pediatr Otorhinolaryngol 1987;13:323-344.

Pyman BC, Brown AM, Dowell RC, and Clark GM. Preoperative evaluation and selection of adults. In Clark GM, Tong YC, and Patrick JF, Eds. Cochlear Prostheses, Chap. 7. London: Churchill Livingstone, 1990:126-134.

Reed CM, Durlach, NI, Delhorne LA, Rabinowitz WM, and Grant $\mathrm{KW}$. Research on tactual communication of speech: Ideas, issues, and findings. Volta Rev Monograph 1989;91(5):65-78.

Weisenberger JM. Tactile aids for speech perception and production by hearing-impaired people. Volta Rev Monograph 1989;91(5): $79-100$.

Acknowledgment: The authors wish to thank Dr. P. Seligman for technical assistance.

Address reprint requests to Robert S. C. Cowan, Research Fellow, Department of Otolaryngology, University of Melbourne, Parkville, 3052, Victoria, Australia.

Received April 4, 1990; accepted August 28, 1990. 


\section{University Library}

\section{- M M N E R VA A gateway to Melbourne's research publications}

Minerva Access is the Institutional Repository of The University of Melbourne

\section{Author/s:}

Cowan, Robert S. C.;Blamey, Peter J.;Sarant, Julia Z.;Galvin, Karyn L.;Alcantara, Joseph I.;Whitford, Lesley A.;Clark, Graeme M.

Title:

Role of a multichannel electrotactile speech processor in a cochlear implant program for profoundly hearing-impaired adults

Date:

1991

Citation:

Cowan, R. S. C., Blamey, P. J., Sarant, J. Z., Galvin, K. L., Alcantara, J. I., Whitford, L. A., et al. (1991). Role of a multichannel electrotactile speech processor in a cochlear implant program for profoundly hearing-impaired adults. Ear and Hearing, 12(1), 39-46.

Persistent Link:

http://hdl.handle.net/11343/27300 